\title{
Actionable climate knowledge: from analysis to synthesis
}

\author{
Holger Meinke ${ }^{1,7, *}$, Rohan Nelson ${ }^{2}$, Phil Kokic ${ }^{3}$, Roger Stone $^{1,6}$, Ramasamy Selvaraju ${ }^{4}$, \\ Walter Baethgen ${ }^{5}$
}

\author{
${ }^{1}$ Department of Primary Industries \& Fisheries, PO Box 102, Toowoomba, Queensland 4350, Australia \\ ${ }^{2}$ CSIRO Sustainable Ecosystems, GPO Box 284, Canberra, Australian Capital Territory 2601, Australia \\ ${ }^{3}$ Australian Bureau of Agricultural and Resource Economics (ABARE), GPO Box 1563, Canberra, \\ Australian Capital Territory 2601, Australia \\ ${ }^{4}$ Tamil Nadu Agricultural University, Coimbatore 641 003, Tamil Nadu, India \\ ${ }^{5}$ International Research Institute for Climate and Society (IRI), Columbia University, PO Box 1000, Palisades, \\ New York 10964-8000, USA \\ ${ }^{6}$ University of Southern Queensland, Faculty of Sciences, Toowoomba, Queensland 4350, Australia \\ ${ }^{7}$ Present address: Wageningen University, Department of Plant Sciences, Crop and Weed Ecology, PO Box 430, \\ 6700 AK Wageningen, The Netherlands
}

\begin{abstract}
The traditional reductionist approach to science has a tendency to create 'islands of knowledge in a sea of ignorance', with a much stronger focus on analysis of scientific inputs rather than synthesis of socially relevant outcomes. This might be the principal reason why intended end users of climate information generally fail to embrace what the climate science community has to offer. The translation of climate information into real-life action requires 3 essential components: salience (the perceived relevance of the information), credibility (the perceived technical quality of the information) and legitimacy (the perceived objectivity of the process by which the information is shared). We explore each of these components using 3 case studies focused on dryland cropping in Australia, India and Brazil. In regards to 'salience' we discuss the challenge for climate science to be 'policy-relevant', using Australian drought policy as an example. In a village in southern India 'credibility' was gained through engagement between scientists and risk managers with the aim of building social capital, achieved only at high cost to science institutions. Finally, in Brazil we found that 'legitimacy' is a fragile, yet renewable resource that needs to be part of the package for successful climate applications; legitimacy can be easily eroded but is difficult to recover. We conclude that climate risk management requires holistic solutions derived from cross-disciplinary and participatory, user-oriented research. Approaches that combine climate, agroecological and socioeconomic models provide the scientific capabilities for establishment of 'borderless' institutions without disciplinary constraints. Such institutions could provide the necessary support and flexibility to deliver the social benefits of climate science across diverse contexts. Our case studies show that this type of solution is already being applied, and suggest that the climate science community attempt to address existing institutional constraints, which still impede climate risk management.
\end{abstract}

KEY WORDS: Climate knowledge · Salience · Credibility · Legitimacy · Dryland cropping · Risk management $\cdot$ Modelling

\section{BACKGROUND}

Climate is recognised as one of the biggest risk factors affecting the performance and management of agricultural systems, from farm management to inter- national commodity trading. Climate variability and change contribute to the vulnerability of individuals, businesses, communities and regions. This influences decision makers at all levels (policy, businesses and farms), regardless of the level of economic develop- 
ment. Climate affects all facets of rural life, including income and food security, and often exacerbates environmental degradation, with downstream effects on national economies (Nelson \& Kokic 2004, Selvaraju 2003). Extreme climate events such as severe droughts, floods, or temperature shocks often strongly impede sustainable agricultural development, particularly in the tropics and sub-tropics (Meinke \& Stone 2005).

Increasing awareness of the impact of climate variability and change on the agricultural sector has led to numerous national and international initiatives that aim to improve decision-making through the application of 'climate knowledge' (Glantz 2005), particularly in regions that are exposed to high climatic variability (e.g. South America, South Africa, Australia and Asia). The CLIMAG program was designed to build on the growing ability to predict future climate variations and to improve agricultural systems management and decision-making at local, national and international scales by establishing global partnerships (Sivakumar 2000). CLIMAG draws on regional expertise and networks, and acts as a conduit to facilitate knowledge and information transfer, co-learning and capacity building. This was a worthwhile initiative, as this Climate Special shows, but also has some problems.

One of the key questions is why the available information is generally not used and embraced by decision makers (Cash \& Buizer 2005). Lack of 'ownership' of the information by the intended end users is clearly one issue and has lead to a growing acceptance among climate scientists that they must move out of their disciplinary confines and engage in a process of continued, shared learning and joint problem solving (Glantz 2003, 2005). In this model, everyone is a stakeholder, and everyone will be affected by the decisions made. This is easy to say, but extremely difficult to implement.

Some critics have argued that current climate forecasts and the way they are presented and disseminated are at best ineffective, while at worst they can increase risk due to inappropriate action by the decision maker (with potentially disastrous consequences), particularly for resource-poor, risk-averse subsistence farmers (e.g. Blench 1999). In the absence of any scientific climate knowledge, management of these agricultural systems evolved to cope with climate variability, often resulting in a wealth of indigenous knowledge relating to climate and weather (e.g. da Cunha 1995, Stigter et al. 2005). This resulted in traditional, riskaverse management practices that usually ensured that subsistence needs were met under adverse conditions, but might be sub-optimal under favourable conditions.

Changing these established risk-management practices without fully understanding the possible impacts of such changes can inadvertently increase exposure to risks, thereby increasing rather than decreasing vulnerability. This problem mainly arises from a poor understanding of how to use climate information for better risk management, often based on the naive assumption that knowledge can be transferred as an unambiguous signal. This is not an intrinsic deficiency of scientifically based climate knowledge; it is more likely a consequence of the complexity of the decisionmaking process and the difficulties of decision makers and scientists to recognise that the knowledge of managing risk resides with both communities (P. Hayman pers. comm.). Traditional approaches to dealing with climate risk often led to very effective risk management strategies long before climate science created possibilities for a more structured means of dealing with risk. Decision makers usually manage risk holistically, while scientific information is generally derived using reductionist approaches; this can lead to a 'disconnect' between scientists and decision makers and to information that, although scientifically sound, often lacks relevance.

A further complication arises from the fact that farmers' actions have environmental consequences and impacts on the social and economic wellbeing of rural communities. This partly drives policy formulation, providing a framework within which farmers execute their management options. More efficient and effective policies would, at least in principle, result from common approaches and technologies that provide decision makers at all levels and scales (from farm/ agribusiness to policy) with more objective, faster and lower-cost information. All stakeholder groups can then objectively compare options, evaluate choices and assess policy or management consequences. Analytical approaches, such as systems modelling, facilitate this process and help stakeholders to identify and choose between inevitable trade-offs along the path to sustainable development (Hammer et al. 2000, Agrawala et al. 2001, Meinke et al. 2006).

Cash \& Buizer (2005) argue that for climate information to translate into real-life action requires 3 essential components, namely: salience, credibility and legitimacy. 'Salience' relates to the perceived relevance of climate information: does the system provide information that these users think they need, in a form and at a time that they can use it? 'Credibility' addresses the perceived technical quality of information: does the system provide information that is perceived to be valid, accurate, tested, or, more generally, at least as likely to be 'true' as alternative views? 'Legitimacy' concerns the perception that the system has the interests of the users in mind or, at a minimum, is not simply a vehicle for pushing the agendas and interests of other actors. 
In the present study we highlight the potential of an integrated systems approach to the management of climate risk. We use a case study approach to show the global relevance of systems analysis and the 3 essential elements discussed by Cash \& Buizer (2005).

In regard to 'salience' we discuss the challenge for climate science to be policy-relevant using Australian drought policy as an example. Australian drought policy is focused on enhancing the self-reliance of farmers to manage climate risk. Self-reliance is a concept intertwined with the vulnerability and resilience of rural communities, which can be influenced by a range of policy measures. However, scientific inputs to Australian drought policy focus on physical measures of the extent to which rural communities are exposed to climate variability, despite the fact that these cannot be influenced by policy in the short to medium term.

'Credibility' is discussed from the perspective of smallholder farmers in India: how can science ensure credibility under such socio-economic conditions? The CLIMAG experience with villages in southern India shows that such credibility can be gained, but that it comes at a high cost with regard to interaction with stakeholders. Such successful engagement can create a community demand for ongoing science-user interactions that the science community might not be able to satisfy beyond the pilot study. Therefore, the attainment of credibility can bear the seeds of its own destruction.

Under the heading of 'legitimacy' we discuss a South American example. Using the Nordeste of Brazil as a case study, we show how easily legitimacy can be eroded and how difficult it is to recover. However, the tide might be turning and even some of the prophetas (informal, rural community leaders with substantial indigenous knowledge regarding climate risk management in their region) are (again?) becoming increasingly interested in the science of climate and its consequences.

\section{EXAMPLE 1-SALIENCE: A 'POLICY-RELEVANCE' GAP IN AUSTRALIA}

In Australia, rainfall variability and its interaction with land management has shaped Australian agriculture since the beginning of European settlement over 200 years ago, and 'drought' remains undoubtedly the biggest climatic issue in Australia. Today climate and agricultural systems research is well developed and highly institutionalised (Cash \& Buizer 2005). To enhance the capacity of the rural sector to cope with - and adapt to the risk of — climate variability and change, the Australian government has embraced the principles of participatory engagement in the design of drought policy. Strictly speaking, drought is a social construct and represents the risk that agricultural activity will be severely disrupted given spatial and temporal variations in rainfall. Australian drought policy encourages primary producers to adopt self-reliant approaches in managing the risks associated with climate variability. It recognises that producers are responsible for managing the commercial performance of their enterprise and for ensuring that agricultural activity is carried out in an economically and environmentally sustainable manner (Botterill 2003). The policy also recognises that drought assistance should not inhibit the natural course of structural adjustment due to other pressures such as declining commodity prices (White \& Karssies 1999, Botterill 2003).

Australian drought policy has developed in the context of deregulation of the agricultural sector to create efficient and internationally competitive farming systems. The policy has multiple objectives that include (adapted from DPTF 1997 and cited in Botterill 2005): (1) encouraging self-reliant approaches to managing climate variability; (2) protecting the natural resource base in times of extreme climate stress; (3) ensuring adequate welfare support for farm families commensurate with that available to other Australians; (4) ensuring that the policy does not impede structural adjustment in the farm sector; and (5) a high level of awareness and understanding of drought and drought policy.

Wilhite (1996) argued that drought policy should be informed by measures of the impact of climate variability on policy-relevant outcomes such as farm incomes and profitability, while Thompson \& Powell (1998) showed how this could be done using wholefarm models. They concluded that a preoccupation with climate and environmental definitions of drought was not consistent with a need to holistically manage all sources of risk on farms. The relevance gap that has emerged between the information necessary to support Australian drought policy, and that being supplied, has been highlighted through the work of Nelson et al. (2005). The resilience of rural livelihoods can be enhanced through policies that increase the diversity of assets and income sources from which rural livelihoods are derived, and the flexibility to switch between them (Ellis 2000). Policies with potential to increase the diversity of farm income sources include investment in production, transport and marketing infrastructure, education and training, regional development, and policies that affect the cost and availability of rural credit (Anderson 2003).

Nelson et al. (2005) showed that the capacity of Australian rural households to cope with risk can be broadly measured through the human, social, natural, physical and financial assets from which rural liveli- 
hoods are derived (Fig. 1A). However, the information used to implement drought policy in Australian agriculture is heavily dominated by reductionist measures of variability in rainfall, soil water and plant growth (Laughlin \& Clarke 2000). Not only is policy largely powerless to influence the impact of climate variability on these scientific measures of exposure to climate risk, they also bear little or no relation to more holistic measures of the key policy outcome: the coping capacity of rural communities (Fig. 1).

The solution to this relevance gap between science and policy objectives lies with overcoming institutional constraints. The evolution of bioeconomic modelling systems demonstrates that it is not methodological constraints that are preventing science from becoming more policy-relevant (Nelson \& Kokic 2004, Nelson et al. 2005). This suggests that there are institutional constraints preventing policy 'demand' from being translated into 'purchases' of policy-relevant science. We suggest that institutional reform is required to realign research capacity and incentives to: (1) change the analytical focus of applied climate science; (2) merge climate variability and climate change research ${ }_{i}$ (3) develop more holistic systems of risk management that considers climate as part of the broader risk management strategies of rural communities; and (4) facilitate sharing of residual riskes between governments, rural communities and individuals.

The science currently provided to inform Australian drought policy is narrowly reductionist and closely confined to disciplinary and institutional boundaries. It provides few insights into the vulnerability of rural communities, which is an emergent property (i.e. more complex effects or behaviours than just the sum of the effects/behaviours of the different components involved) of complex human-environment interactions that can only be understood through integrated, multidisciplinary approaches. The potential for scientists to pursue their own agendas in channelling the supply of narrow disciplinary information has long been recognised (Russell 1938, Holling 1978), and continues to be a critical issue in natural resource governance (Brunner \& Steelman 2005). The establishment of an independent drought monitoring authority is often cited as an option for improving the implementation of Australian drought policy (Botterill 2005, White et al. 2005).

Over-reliance on reductionist and self-interested science can be overcome by realigning funding and other incentives in order to break down monopolies on policy advice. An alternative is to provide incentives for the multi-disciplinary and cross-institutional cooperation necessary to deliver integrated information on policy outcomes. This will encourage scientists to step outside their disciplinary and institutional comfort zones to develop multidisciplinary approaches that provide more integrated and holistic insights into the vulnerability of rural communities. Policy advisers can help by providing funding incentives for scientists to break free of narrow disciplinary and institutional interests. As Meinke et al. (2006) pointed out, this also requires that scientists engage with stakeholdersdecision makers at the farm and agribusiness levels, as well as policy makers - to facilitate informed discussion on drought policy and the integrated science necessary to support it. Only then can policy relevant drought science be continuously realigned with changing policy priorities.
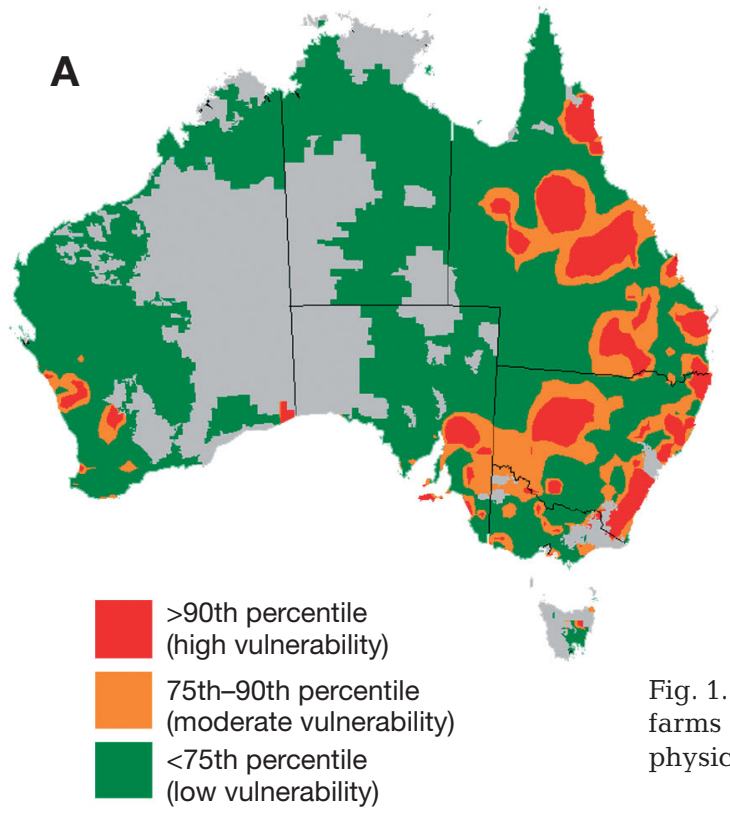

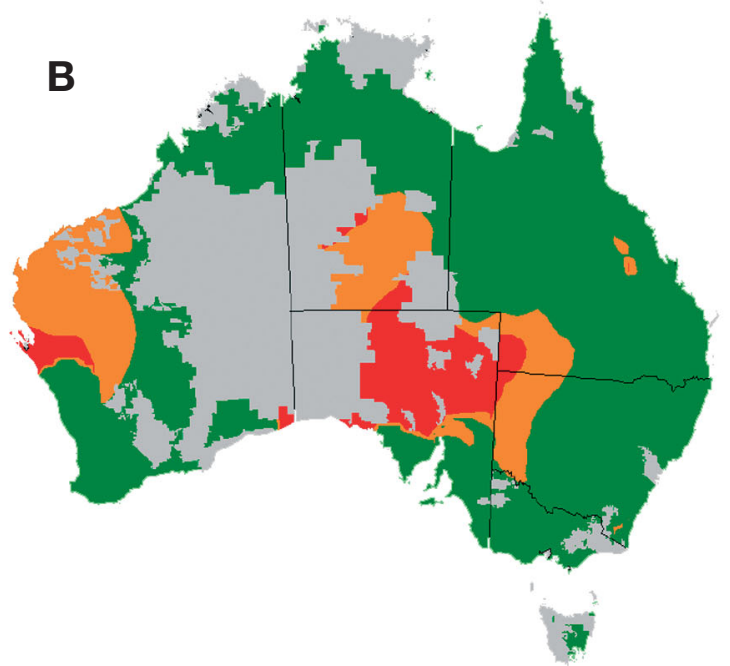

Fig. 1. Standardised indices of the vulnerability of Australian broadacre farms using (A) equally weighted indices of human, social, natural, physical and financial capital, and (B) a single measure of extreme pasture growth 
Current research into managing climate risk in Australia is fragmented, often conducted within narrow disciplinary and institutional boundaries, and focused on the simplest physical definitions of climate risk that are easiest to measure. This reflects a pervasive historical influence of positivism across natural resource management more generally. At any one time, our knowledge based on reductionist science is fragmented by disciplinary interests and differential rates of progress across diverse fields of inquiry (Brunner \& Steelman 2005). Over-reliance on quantitative approaches risks narrowing the focus of inquiry to aspects that are easier to measure (Backhouse 2002). As recognised by the Scottish philosopher David Hume in the 18th century, the backward looking nature of empirical inference also reduces its ability to handle new and unexpected future conditions (Nagel 2005). More recently, Lowe (2002) has argued that many, particularly environmental problems, are actually the result of applying narrow, specialised knowledge to complex systems. He describes modern science as 'islands of understanding in oceans of ignorance' and calls for 'scientists and practitioners to work together to produce trustworthy knowledge that combines scientific excellence with social relevance'.

Beyond engaging with public policy makers, publicprivate partnership models need to be explored further in order to 'mainstream' climate risk management. Mainstreaming involves integrating climate riskmanagement tools and approaches into holistic livelihood strategies that simultaneously recognise and manage other sources of risk, such as market fluctuations and threats to the natural resource base. It can also involve communicating strategies for managing climate risk through communication networks set up for other purposes, rather than pursuing climate-specific communication programs. These initiatives need to be supported by the implementation of integrated information systems capable of informing the biophysical, economic and social impacts of climate variability and change. Although systems of this kind have been developed to support policy (Nelson \& Kokic 2004, Nelson et al. 2005), institutional barriers currently impede their implementation. A dynamic process of incentive realignment and institutional reform supported by independent review is required to constantly refocus scientists and their institutions on the policy outcomes of critical importance to governments and rural communities.

\section{EXAMPLE 2-CREDIBILITY: CREATING SOCIAL CAPITAL IN INDIA}

Dryland agriculture in India occupies nearly $70 \%$ of the total cultivable area, most of which is arid or semiarid. India's drylands are largely mono-cropped during the summer monsoon season (June to September). In Tamil Nadu State, at the extreme south of the Indian Peninsula, significant rainfall in both the summer and winter (October to December) monsoon seasons (Dhar et al. 1982) permits double cropping, resulting in higher average annual production, but also greater production risk and frequent crop failures (Selvaraju et al. 1999). High inter-annual rainfall variability exposes these dryland cropping systems to considerable risks. The El Niño-Southern Oscillation (ENSO) accounts for a significant proportion of rainfall variability in this region (Parthasarathy \& Pant 1985, Sridharan \& Muthusamy 1990, Selvaraju 2003). Continuous exposure of these fragile agricultural systems to such a variable rainfall regime may lead to low levels of resilience, which might push these systems beyond recovery (soil erosion, unserviceable debt levels etc.). This continued exposure to climate risk has already increased income inequality among the resource-poor farmers in this region, thereby limiting sustainable development. A simulation-based analysis shows that ENSO related climate indicators such as the Southern Oscillation Index phases (SOI phases; Stone et al. 1996) explain some of the variability in crop yields and associated income (Fig. 2). However, communicating such probabilistic information to local communities that have never been exposed to such external information presented a major challenge.

Given this opportunity, we approached this problem through a participatory risk management paradigm, employing concepts of social capital. Social capital here refers to the institutions, relationships, and norms that shape the quality and quantity of a society's social interactions. Social capital is not just the sum of the

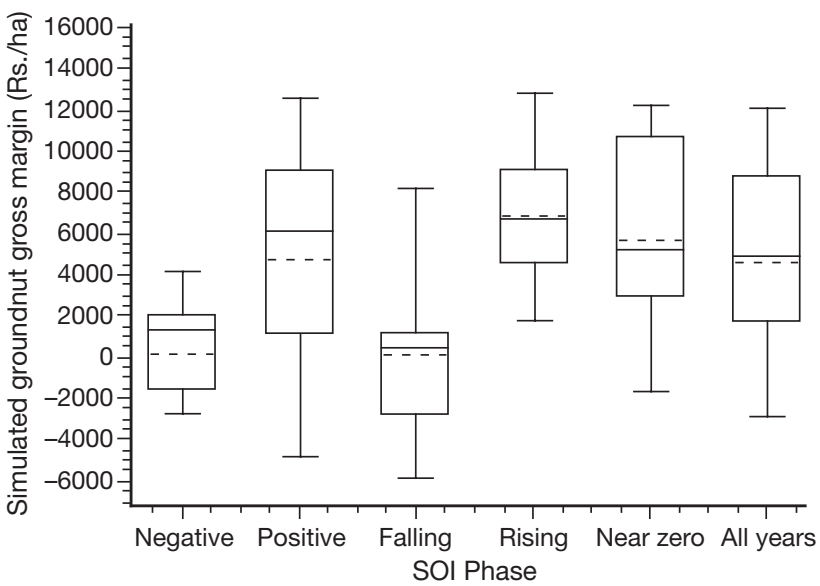

Fig. 2. Distributions of simulated groundnut gross margin at Avinashi, India, for years associated with each of the five April-May phases of the Southern Oscillation Index (SOI) and for all years. Gross margin values for each SOI phase-dashed line: median; solid line: mean; bottom (top) of box: 75th (25th) percentile; bottom (top) whisker: 90th (10th) percentile 
institutions that underpin a society; it is the trust that holds them together. Our efforts were targeted towards creating social capital within the local community as a unit. The approach is based on the assumption that providing credible information to farmers can motivate them to take pro-active management decisions. We postulate that 'good' climate risk management depends on various dimensions of social capital, namely peer groups, networks, trust, collective action, social inclusion, information and communication. These dimensions capture both the structural and cognitive forms of social capital.

Evidence shows that social cohesion is critical for societies to prosper economically and for development to be sustainable. We also see social capital as a focus for the delivery of organized and usable climate knowledge that ensures development within the community. Maintaining and enhancing social capital depends critically on the ability of the members of a community to communicate among each other, with other communities, and with members of their networks that live outside the community (Putnam 1993).

In order to investigate if climate information can add value to existing risk management frameworks, we conducted a case study at village scale (Thamaraikulam in Avinashi sub-district in Tamil Nadu). This village was chosen, because it already had an effective extension network in place, and because initial desktop studies suggested that climate information could improve profitability and sustainability of current systems management.

In order to understand the farmers' current climate risk management strategies, we closely monitored all on-farm decisions for the 2002 summer monsoon season. To this end we established participatory climate risk-management workshops with the initial aim of simply providing a forum for peer-to-peer discussions. This allowed us to gather the following baseline information: The total geographical area of the village is 641 ha with a total population of 1323. A total cultivable area of 560 ha is dominated by dryland cropping (>75\%) and operated by 313 farmers. On average, 411 ha $(73.3 \%)$ of total cultivable area were allotted to cotton, sorghum and groundnut during the summer monsoon season. In post-season workshops, we elicited feedback about the climate information provided, actual changes in management and their outcomes. We estimated the change in area under individual crops using monthly area planted data collected from the village administrative office.
After our initial model-based analysis, we conducted pre-season farmer participative workshops, in which we presented and discussed the shifts of rainfall probabilities and potential management responses. We discussed the probability that seasonal rainfall, crop yield and gross margin (current costs and prices) would exceed their medians. We discussed with farmers the high probability of below-normal rainfall associated with falling April to May and negative May to June SOI phases. Simulations indicated high likelihood of reduced groundnut and cotton yield, which could be mitigated by choosing sorghum as an alternative crop. We also discussed distributions of predicted yields and associated gross margins for cotton. Discussions concentrated on the trade-offs between increased risks of incurring losses from cash crops (groundnut and cotton) versus the risk of not realising a profit from these crops, should a good season eventuate.

Discussions of model-derived management options with farmers appeared to influence the aggregate agricultural land use (i.e. crops allocated) in our case study village. Many farmers indicated during our inseason discussions and post season workshops that they changed from growing cotton to early sorghum in July 2002. More than $70 \%$ of farmers grew at least some sorghum that season, which until then was not an established risk management practice in this region. The $20 \%$ of farmers who planted cotton had to abandon their crops by August, losing all their input costs. Table 1 shows the actual area planted in different months during the 2002-2003 cropping seasons and 2003-2004. It also shows percent change from the previous 8 yr average (using the 1994-1995 to 2001-2002 seasons as a base line). Of the 91 small and medium farmers we contacted during post-season

Table 1. Actual area planted (ha) and \% change from 8 yr mean (the 1994-1995 to 2001-2002 seasons were used as the baseline period) for major crops during the 2002-2003 and 2003-2004 cropping seasons at the case study village in India (Thamaraikulam near Avinashi, western agro-climatic zone, Tamil Nadu). NA: not applicable

\begin{tabular}{|c|c|c|c|c|c|c|}
\hline & \multicolumn{2}{|c|}{$\begin{array}{c}\text { Groundnut } \\
\text { Area \% Change }\end{array}$} & \multicolumn{2}{|c|}{$\begin{array}{l}\text { Cotton } \\
\text { Area \% Change }\end{array}$} & \multicolumn{2}{|c|}{$\begin{array}{c}\text { Sorghum } \\
\text { Area \% Change }\end{array}$} \\
\hline \multicolumn{7}{|c|}{$2002-2003$ season } \\
\hline June & 3.0 & -95 & 0 & NA & 0 & NA \\
\hline July & 5.2 & -9 & 10.0 & -92 & 70.0 & +187 \\
\hline August & 42.3 & -7 & 4.5 & -97 & 7.3 & -91 \\
\hline September & 0 & NA & 67.0 & 93 & 210.9 & +121 \\
\hline Total & 50.5 & -33 & 81.5 & -60 & 288.2 & 80 \\
\hline \multicolumn{7}{|c|}{ 2003-2004 season } \\
\hline June & 0 & NA & 0 & NA & 0 & NA \\
\hline July & 123 & +106 & 140 & +12 & 26.2 & +8 \\
\hline August & 0 & NA & 0 & NA & 93.0 & +23 \\
\hline September & 0 & NA & 0 & NA & 0 & NA \\
\hline Total & 123.0 & +70 & 140.0 & -30 & 119.2 & -26 \\
\hline
\end{tabular}


workshops and thereafter, 37 indicated that they had changed to early sorghum. We attribute most of the $187 \%$ increase in area under sorghum during July 2002 to the community-wide discussions of climate forecasts and response options, given that the 70 ha of sorghum planted in July 2002 was the highest in the past 8 yr (average 24.4 ha).

We observed strong 'lateral seepage' from the farmer groups, with information reaching the majority of the farmers in the village. Farmer groups and networks, such as the ones established in our case study, improve active connections among people: they create trust, mutual understanding, and shared values and behaviours that bind the members of farmer networks and communities and make cooperative action possible (Cohen \& Prusak 2001). In our case study, the farmer networks that constitute social capital served as conduits for the flow of useful climate knowledge, helping the farmers to reduce climate-related risk.

The participative climate workshops improved the community's capacity to work together to address their common needs, fostering greater inclusion and cohesion, and increasing transparency and accountability. A principal goal of our approach was to provide guidance on how improved social capital can lead to proactive decision-making using climate knowledge. In our example, climate forecasts linked with participatory efforts to disseminate crop model-based information were used to evaluate and guide climatic risk management in crop production. Farmers' management practices and their 'rules of thumb' formed the basis for all our analyses.

Our pilot study helped to build the credibility of a scientific climate risk management approach. We are, however, unsure that our activities were sufficient to build enough social capital for sustained science-user interactions in this region. We are concerned that creating credibility via such pilot studies might in fact increase the demand for services that cannot be satisfied beyond the pilot stage. This can lead to resentment and disenfranchisement of interested farmers that could lead to non-adoption of potentially very useful risk-management approaches. If this is the case, our efforts to increase the credibility of a scientific approach to climate risk management might contain the seeds for its own destruction. As in the Australian case study on the importance of saliency, we argue that 'mainstreaming' climate risk management approaches within the context of overall rural livelihood strategies is required. In order to create sufficient social capital for sustained science-user interactions, climate knowledge needs to be communicated via functional, existing communication networks of farmers and other landholders, rather than pursuing climate-specific communication programs.

\section{EXAMPLE 3-LEGITIMACY: A FRAGILE, YET RENEWABLE RESOURCE}

The loss of legitimacy-and hence of the ability to make a scientific contribution to benefit society - can happen quickly and comprehensively. Regaining legitimacy is a much harder, slower process. Here we demonstrate this point using the Brazilian Nordeste as a case study. This region covers 9 Brazilian states: Maranhao, Piaui, Rio Grande do Norte, Ceara, Paraiba, Pernambuco, Alagoas, Sergipe and Bahia.

The Brazilian Nordeste suffers from regular drought, defined as a season with insufficient quantity or distribution of rainfall to obtain a viable crop harvest. The frequency of droughts has increased, and recently 5 droughts were recorded in just 1 decade (Finan 1999).

Scientific information and products often provide policy makers with apolitical tools that can insulate decision-making from highly politicized environments. In the specific case of seasonal forecasts in the Nordeste, they are also viewed as tools that can assist in the prediction of extreme events, which were previously perceived as unpredictable, and are therefore helpful to prepare societies to confront extreme events such as drought or floods, and to mitigate their impacts (Lemos 2003).

The Meteorology and Hydrology Service (FUNCEME) of the Brazilian State of Ceará has been very active in providing credible, technical information on climate, hydrological conditions and soil moisture to water resource managers and the agricultural community across the 9 states of the Nordeste. The important role that FUNCEME plays in the water resources management and in the agricultural sector of Ceará has been widely documented (Lemos et al. 1999 2004, Lemos 2003, Taddei 2005).

'Hora de Plantar' (Time to Sow), initiated in 1988, was a program in which the government of Ceará distributed high-quality hybrid seed to small farmers at the time when soil moisture conditions were supposedly adequate to ensure a good crop. FUNCEME provided the vital soil and climate information used in 'Hora de Plantar', as well as the seasonal forecasts that were perceived as affecting the seed distribution program. Although seasonal forecasts, also produced by FUNCEME, were not specifically included in the program, there was a general perception throughout the farming community that seed distribution was strongly influenced by FUNCEME's forecasts (Lemos 2003).

Traditionally farmers in Ceará, as in most semiarid regions of the world, start planting their crops as soon as the first rains come. In the case of the Nordeste, farmers are specially inclined to use this strategy, because in years with good rainfall they may be able to harvest 2 consecutive crops in the same rainy season 
(Lemos 2003). The first seasonal rains in Ceará are often the result of cold fronts coming from the south, (and as such are not associated with the actual, monsoon-related rainy season), a phenomenon that remains difficult to predict at the seasonal scale. Early-sown crops very often fail due to lack of soil moisture, and farmers sow again as soon as the next rains come. This traditional strategy of frequent serial sowings is only viable with inexpensive (non-hybrid) seed: if the rains are good, farmers may be able to double crop, and if the rains are sparse, sowing several times increase their chances of getting at least one crop in the season. Hence farmers usually save some seed from the previous season. After a drought, however, small farmers often exhausted their seed reserves and relied on seed distributed via the 'Hora de Plantar' program.

Although the 'Hora de Plantar' program was successful in several seasons, it also created strong resistance within the farmer community. From a traditional risk-management perspective it is crucial for farmers in Ceará to take advantage of the early rains in order to have at least a small chance of getting 2 harvests. The perception of the farmers was that the program often distributed seed when it was too late for early sowing. The program was especially criticized in the years when the early rains were abundant for a good early crop and farmers did not get their seed in time (many farmers perceived this situation as a 'sinful waste of precious rain', Lemos 2003). Consequentlyand regardless of the actual outcome-the program was perceived as transferring control of the decisionmaking process from individual farmers to government officials, thereby disempowering farmers.

Due to the close connection between 'Hora de Plantar' program and FUNCEME, the discontent of the farmer community with the program also eroded the perceived prestige and legitimacy of FUNCEME's work. Moreover, this reinforced the perception of FUNCEME as a public agency serving political interests instead of providing technically and scientifically sound assistance to the farming community.

In the past few years FUNCEME has made substantial efforts to reverse this situation and regain their legitimacy. The agency began to distance itself from the 'Hora de Plantar' program and publicly clarified its real role in the program. Simultaneously, FUNCEME began implementing participatory activities in the agricultural sector, including the development of new methods for communicating their seasonal climate forecasts as well as in educating the agricultural stakeholders and the general public (including the media) in the probabilistic nature of the climate forecasts (R. R. Taddei pers. comm.). Finally, FUNCEME started to produce its forecasts in close collaboration with the International Research Institute for Climate and Soci- ety (IRI) of Columbia University, as well as with other international agencies. This collaboration with wellknown international institutions, the implementation of participatory activities throughout the state, and the changes in the communication strategy have allowed FUNCEME to slowly regain its position as a credible, objective and scientifically competent agency that does not serve political interests.

This is a slow and on-going process, which is so far backed only by anecdotal evidence. During 2004 the project team conducted several informal farmer interviews in the Limoeiro do Norte district. FUNCEME's change in approach and their scientific contribution to climate risk management were acknowledged by Limoeiro's farmers, who include local rural leaders recognised for their application of indigenous climate knowledge (the local 'profetas'). They expressed interest in using FUNCEME's products for decisions such as selling cattle early to avoid feed shortages when drought conditions are likely, or paying more attention to early sown crops when the probabilities for a good season are higher. Clearly, a more formal evaluation process, as well as the documentation of farmers' attitude towards FUNCEME's new approach, are desirable.

\section{CONCLUSIONS}

Salience requires that scientists expand their horizons beyond disciplinary boundaries and fully explore tensions and interactions between science and policymaking, and between science and socio-economic forces. Vision and strong leadership is required to induce cultural change in established institutional arrangements. Participatory engagement is required to increase the capacity of policy advisers to make informed purchases of multi-disciplinary systems science. The system we are dealing with is more extensive than was previously thought. We need to move beyond rhetoric and integrate climate science into the socio-economic dimensions important to rural communities and policy makers. This is not a case of 'either/ or'; $^{\prime}$ we need to achieve integration of disciplinary knowledge, rather than focusing on certain aspects of the system at the exclusion of others.

Credibility is essentially derived from social contracts between climate scientists and those affected by climate risk. The Indian experience reported here demonstrates that climate science can be infused into processes that build the types of social capital which can help improve resilience within rural communities. In doing so it demonstrates that science derives credibility not just from its technical precision, but also from the appropriate design of the engagement processes 
via which it is delivered. How this process can be sustained, particularly within resource-poor farming communities, remains an open question.

Legitimacy is a fragile, yet renewable resource. Legitimacy is essential for scientific content to have influence-without it potentially valuable information will not be translated into 'actionable knowledge' and the scientific content will remain without its intended benefits for society. Organisations need to recognise the importance of legitimacy as a resource that cannot be created through simply delivering reductionist science. In fact, as our example showed, such an approach can easily lead to a loss of legitimacy from which it can be very difficult to recover. We suggest that legitimacy needs to be built and managed as a pathway to influence and empower people.

Acknowledgements. The authors are grateful for financial support from the Asia Pacific Network for Global Change Research (APN) and the Inter-American Institute for Global Change Research (IAI). H.M., R.N. and R.S. are also members of the Agricultural Production Systems Research Unit (APSRU), an unincorporated joint venture.

\section{LITERATURE CITED}

Agrawala S, Broad K, Guston DG (2001) Integrating climate forecasts and societal decision making: challenges to an emergent boundary organization. Sci Technol Hum Values 26:454-477

Anderson JR (2003) Risk in rural development: challenges for managers and policy makers. Agric Syst 75:161-197

Backhouse R (2002) The Penguin history of economics. Penguin Books, London

Blench R (1999) Seasonal climate forecasting: Who can use it and how it should be disseminated? Nat Resour Perspect 47, Overseas Development Institute, London. Available at: www.odi.org.uk/nrp/47.html

Botterill LC (2003) Uncertain climate: the recent history of drought policy in Australia. Aust J Polit Hist 49(1):61-74

Botterill LC (2005) Late twentieth century approaches to living with uncertainty: the national drought policy. In: Botterill LC, Wilhite D (eds) From disaster response to risk management: Australia's national drought policy. Springer, Dordrecht

Brunner R, Steelman T (2005) Beyond scientific management. In: Brunner R, Steelman $T$, Coe-Juell $T$, Cromley $C$, Edwards C, Tucker D (eds) Adaptive governance: integrating science, policy and decision making. Columbia University Press, New York

Cash D, Buizer J (2005) Knowledge-action systems for seasonal to interannual climate forecasting: summary of a workshop, report to the Roundtable on Science and Technology for Sustainability, Policy and Global Affairs. The National Academies Press, Washington, D.C. Available at: http://books.nap.edu/catalog/11204.html

Cohen D, Prusak L (2001) In good company: how social capital makes organizations work. Harvard Business School Press, Boston, MA

da Cunha E (1995) Rebellion in the backlands. University of Chicago Press (first published in 1902)
Dhar ON, Rakhecha PR, Kulkarni AK (1982) Fluctuations in northeast monsoon rainfall of Tamil Nadu. Int J Climatol 2: 339-345

DPTF (Drought Policy Task Force) (1997) Review of the national drought policy. Task force of officials from the Commonwealth, State and Territory Governments, Canberra

Ellis F (2000) Rural livelihoods and diversity in developing countries. Oxford University Press, Oxford

Finan T (1999) Drought and demagoguery: a political ecology of climate variability in Northeast Brazil. Bureau of Applied Research in Anthropology. Paper from workshop on: 'Public Philosophy, Environment, and Social Justice'. Carnegie Council on Ethics and International Affairs, Merrill House, New York, NY

Glantz MH (2003) Climate affairs: a primer. Island Press, Washington, DC

Glantz MH (ed) (2005) Usable science 9: El Niño early warning for sustainable development in Pacific Rim countries and islands. Report of workshop held 13-16 September 2004. ISSE/NCAR, Boulder, CO

Hammer GL, Nicholls N, Mitchell C (eds) (2000) Applications of seasonal climate forecasting in agricultural and natural ecosystems: the Australian experience. Kluwer, Dordrecht

Holling C (ed) (1978) Adaptive environmental assessment and management. Blackburn Press, Caldwell

Laughlin G, Clarke A (2000) Drought science and drought policy in Australia: a risk management perspective. In: Wilhite A, Sivakumar MVK, Wood DA (eds) Early warning systems for drought preparedness and drought management. Proc Expert Group Meet on Early Warning Syst Drought Prep, 5-7 September. Bureau of Rural Sciences, Department of Agriculture, Fisheries and Forestry, Kingston. Available at: www.affa.gov.au/corporate_docs/ publications/pdf/rural_science/Lisbon14.pdf

Lemos MC (2003) A tale of two polices: the politics of climate forecasting and drought relief in Ceará, Brazil. Policy Sci 36:101-123

Lemos MC, Nelsom D, Finan T, Fox R, Mayorga D, Mayorga I (1999) The social and policy implications of seasonal forecasting: a case study of Ceará, Northeast Brazil. NOAA Final Report, Award \# NA76GPO385. Available at: www.rmportal.net/groups/ua_developers/Publications/thesocial-and-policy-implications-of-seasonal-forecasting-acase-study-of-ceara-northeast-brazil

Lemos MC, Farias de Oliveira JL (2004) Can water reform survive politics? Institutional change and river basin management in Ceará, Northeast Brazil. World Dev 32(12): 2121-2137

Lowe I (2002) The need for environment literacy. ALNARC Online Forum, ANTA National Literacy Project, Australian Government Department of Education, Science and Training (DEST), Queensland. Available at: www. staff.vu.edu.au/alnarc/onlineforum/AL_pap_Lowe.htm

Meinke H, Stone RC (2005) Seasonal and inter-annual climate forecasting: the new tool for increasing preparedness to climate variability and change in agricultural planning and operations. Clim Change 70:221-253

Meinke H, Howden M, Nelson R (2006) Integrated assessments of climate variability and change for Australian agriculture: connecting the islands of knowledge. Proc 3rd Biennial meeting of the Int Environ Model Software Soc, July (CD ROM). International Environmental Modelling and Software Society, Burlington, VT. Available at: www. iemss.org/iemss2006/sessions/all.html

Nagel T (2005) Induction. In: Honderich T (ed) The Oxford 
companion to philosophy, 2nd edn. Oxford University Press, Oxford

Nelson R, Kokic P (2004) Forecasting the regional impact of climate variability on Australian crop farm incomes. ABARE eReport 04.23. Grains Research and Development Corporation, Canberra

Nelson R, Kokic P, Elliston L, King J (2005) Structural adjustment: a vulnerability index for Australian broadacre agriculture. Aust Commodities 12(1):171-179

Parthasarathy B, Pant GB (1985) Seasonal relationship between Indian summer monsoon rainfall and the Southern Oscillation. Int J Climatol 5:369-378

Putnam RD (1993) Making democracy work: civic traditions in modern Italy. Princeton University Press, Princeton, NJ

Russell B (1938) Power: a new social analysis. Routledge, London

Selvaraju R (2003) Impact of El Niño-Southern Oscillation on Indian foodgrain production. Int J Climatol 23:187-206

Selvaraju R, Subbian P, Balasubramanian A, Lal R (1999) Land configuration and soil nutrient management options for sustainable crop production on alfisols and vertisols of southern peninsular India. Soil Tillage Res 52:203-216

Sivakumar MVK (eds) (2000) Climate prediction and agriculture. Proc START/WMO Int Workshop, Geneva, 1999. International START Secretariat, Washington, DC

Submitted: July 8, 2005; Accepted: August 14, 2006
Sridharan S, Muthusamy A (1990) North East monsoon rainfall in relation to El Niño and Atlantic hurricane frequency. Vayu Mandal 41:108-111

Stigter CJ, Dawei Z, Xurong M, Onyewoto LOZ (2005) Using traditional methods and indigenous technologies for coping with climate variability. Clim Change 70:255-271

Stone RC, Hammer GL, Marcussen T (1996) Prediction of global rainfall probabilities using phases of the Southern Oscillation Index. Nature 384:252-255

Taddei RR (2005) Of clouds and streams, prophets and profits: the political semiotics of climate and water in the Brazilian Northeast. PhD dissertation, Columbia University, New York

Thompson D, Powell R (1998) Exceptional circumstances provisions in Australia: is there too much emphasis on drought? Agric Syst 57(3):469-488

White D, Botterill L, O'Meagher B (2005) At the intersection of science and politics: defining exceptional drought. In: Botterill LC, Wilhite D (eds) From disaster response to risk management: Australia's national drought policy. Springer, Dordrecht

White DH, Karssies L (1999) Australia's national drought policy: aims, analyses, and implementation. Water Int 24(1):2-9

Wilhite DA (1996) A methodology for drought preparedness. Nat Haz 13(3):229-252

Proofs received from author(s): November 24, 2006 